\title{
Ventricular Repolarization Abnormality
}

National Cancer Institute

\section{Source}

National Cancer Institute. Ventricular Repolarization Abnormality. NCI Thesaurus. Code C102574.

An electrocardiographic finding of an abnormality of T wave duration or morphology or of early repolarization. (CDISC) 